NOTICE: this is the author's version of a work that was accepted for publication in Archives of Psychiatric Nursing.

Changes resulting from the publishing process, such as peer review, editing, corrections, structural formatting, and other quality control mechanisms may not be reflected in this document. Changes may have been made to this work since it was submitted for publication. A definitive version was subsequently published in Archives of Psychiatric Nursing, Vol. 28 (2014). DOI: 10.1016/j.apnu.2014.08.003 


\section{THE SILENCE OF MENTAL HEALTH ISSUES WITHIN UNIVERSITY ENVIRONMENTS: A QUANTITATIVE STUDY}

Professor Dianne Wynaden, PhD RN CMHN (Corresponding author)

Professor Mental Health

School of Nursing and Midwifery

Curtin University

GPO Box U 1987

Perth, Western Australia 6945

Australia

d.wynaden@curtin.edu.au

Phone +61 892662203, fax +61892662959

Professor Margaret McAllister, EdD RN CMHN

Professor of Nursing

Central Queensland University,

90 Goodchap Street Noosaville 4566

Queensland, Australia

Phone +61407280939 fax +610749306402

m.mcallister@cqu.edu.au

Dr Jenny Tohotoa PhD

Research Officer

School of Nursing and Midwifery

Curtin University

GPO Box U 1987

Perth, Western Australia 6945

Australia

J.Tohotoa@curtin.edu.au

Phone +61 892662958 fax +61892662959

Dr Omar AL Omari PhD RN

Assistant Professor

School of Nursing and Midwifery

Jerash University

Jordan - Jerash

Amman, Irbid international Street

26150 Jerash, Jordan

o.alomari@jpu.edu.jo

Dr Karen Heslop PhD RN

Lecturer

School of Nursing and Midwifery

Curtin University

GPO Box U 1987 
Perth, Western Australia 6945

Australia

Phone +61892662090 , fax +61892662959

K.Heslop@curtin.edu.au

Dr Ravani Duggan PhD RN RM

Senior Lecturer and Associate Director of Undergraduate Studies

School of Nursing and Midwifery

Curtin University

GPO Box U 1987

Perth, Western Australia 6945

Australia

Phone +61892662055 , fax +61892662959

R.Duggan@curtin.edu.au

Dr Sean Murray PhD

Head, Counselling \& Disability Services

Curtin University

GPO Box U 1987

Perth, Western Australia 6845

Australia

Phone +61 892667850, fax 92663052

S.Murray@curtin.edu.au

Professor Brenda Happell PhD RN

Engaged Research Chair in Mental Health Nursing, Director of the Institute for Health and Social Science Research and Director of the Centre for Mental Health Nursing Innovation

Central Queensland University Rockhampton,

Building 18, Bruce Highway,

North Rockhampton 4702

Queensland, Australia

Phone +61 (7) 4923 2164, fax +610749306402

b.happell@cqu.edu.au

Dr Louise Byrne PhD

Lecturer in Lived Experience Mental Health

School of Nursing and Midwifery

Central Queensland University Rockhampton,

Building 18, Bruce Highway,

North Rockhampton, 4702

Queensland, Australia

Phone +61 074923 273, fax +610749306402

l.byrne@cqu.edu.au

Disclaimer: The authors declare no conflict of interest. 


\section{ABSTRACT}

Background: Mental health problems in university students are increasing in frequency and severity and have a substantial bearing on students' ability to complete their university programs. Discrimination and stigma are present in the university environment and impact on students in many ways. Mental health problems occurring in staff are also relatively unexplored but they appear to have an influence on university productivity and staff wellbeing.

Objectives: To determine: 1) attitudes towards mental illness in staff working at two universities in Australia; and, 2) student experiences of stigma within these university environments.

Design: Descriptive study that examined the attitudes and experiences of staff and student towards mental health problems.

Settings: Two universities in two states of Australia.

Participants: University staff and students who agreed to participate in a research study during mental health week in October 2013.

Methods: All staff and students were invited to participate in the research. Staff were asked to complete the "Attitude towards mental illness survey", and students who self-identified as having a mental health problem were asked to complete the "Stigma scale". Both quantitative data collection tools have been used in previous international studies.

Results: Data from 270 staff and 201 students were collected using an online collection process and analysed using Statistical Package for Social Sciences, Version 22.0. The findings show that both students and staff hide their problems and are reluctant to disclose to others for fear of stigma and discrimination. As a result, the silence surrounding mental health problems permeates throughout the university environment. It impacts on help seeking behaviours, the provision of support as well as on the recovery and wellbeing of affected individuals.

Conclusions: University strategic plans must decrease stigma and foster social inclusion, a fundamental principle to build self-esteem and to facilitate recovery in people who have mental health problems. 


\section{Highlights}

- Mental health problems are common in university students and staff

- Fear, and discrimination create a "silence" about mental health problems

- Failure to disclose mental health problems impacts on student educational outcomes.

- Increased mental health literacy can support improved outcomes for students.

Key words: Mental health issues, university students, university staff, stigma and discrimination

\section{INTRODUCTION}

A mental illness is classified as a "health problem that significantly affects how a person feels, thinks, behaves, and interacts with other people (Australian Health Ministers, 2007), and worldwide around one in five people will develop a mental illness (Steel et al., 2014). The Australian National Mental Health and Wellbeing Survey (2007) (Australian Bureau of Statistics, 2009), reported that $26 \%$ of young adults aged between 16 and 24 years, met the International Classification of Diseases $10^{\text {th }}$ Version (ICD-10) (World Health Organization, 1993), criteria for a diagnosis of a mental illness and had experienced symptoms in the previous 12 months.

International research into self-reported and objectively rated levels of psychological distress in university-aged young adults aged between 18 and 25 years reinforced that mental health problems are common in this population (Bayram \& Bilgel, 2007; Field, Diego, Pelaez, Deeds \& Delgado; 2009; Burris, Brechting, Salsman \& Carlson, 2009; Khawaja \& Dempsey, 2007; Leahy et al., 2010; Stallman, 2010; Wynaden, 
Wichmann, \& Murray, 2013; Yorgason, Linville \& Zitzman, 2008), and appear to be growing in both number (Hunt \& Eisenberg, 2010). An Australian study identified that more than $50 \%$ of students across three universities had levels of psychological distress indicative of mental illness in the four weeks prior to accessing professional help. Their level of distress was greater than reported data for the general population (Stallman \& Shochet, 2009) and was also significantly associated with the number of days students were unable to meet their work and study commitments (Stallman, 2008). Despite the interference to their capacity, young people continue to delay or fail to seek help for the problems they are experiencing. This means that at any one time there are a number of students trying to complete their university studies while managing an emerging mental illness or high levels of psychological distress that are causing them increasing concern (Wynaden et al., 2013).

In managing the distressing symptoms associated with a mental health problem, students may draw on their past coping mechanisms which may be healthy or unhealthy responses. For example, they may use alcohol and drugs or access health care services with somatic expressions such as headaches, general malaises, and/or sleep disturbances (Ahern, 2009; Mori, 2000). However, if the underlying cause of the problem remains unresolved, it may continue to impact on the individual, interfere with social interactions with other people and reduce the person's overall level of functioning (Raunic \& Xenos, 2008). Unresolved problems may also affect their ability to meet their educational goals and lead to increased levels of stress, lowered productivity and/or increased absenteeism (Cook, 2007). Low treatment rates for mental health problems in a cross sectional Australian study with 955 tertiary students suggests that traditional models of support may be inadequate or not appropriate for tertiary cohorts (Leahy et al., 2010). Furthermore, 
there are increasing numbers of domestic and international students from Indigenous (First Nation) and culturally and linguistically diverse backgrounds that require models of support that are culturally sensitive and secure. Staff must also have knowledge and understanding of these students' help seeking behaviours (Hyun, Quinn, Madon, \& Lustig, 2007 ; Khawaja \& Dempsey, 2007; Liu, 2009), to increase their willingness to access help and support.

Attitudes and stigma can also determine help seeking intentions (Wynaden et al., 2005) and one of the most cited reasons why people do not seek help for mental health problems is the fear of experiencing discrimination and stigma (Michaels, López, Rüsch, \& Corrigan, 2012; Zartaloudi \& Madianos, 2010). Mental healthrelated stigma can be separated into two components: discrimination (being treated unfairly/differently) and prejudice (stigmatising attitudes) (Clement et al., 2013 ). Stigma and discrimination reduce students' initiative to engage in help seeking behaviour for a variety of reasons (Henderson, Evans-Lacko, \& Thornicroft, 2013). It is imperative that university services facilitate early intervention for, and improved support to these students (Kim, Coumar, Lober, \& Kim, 2011). Whilst it is unrealistic to expect all university staff to have the expertise to work effectively with these students, university environments need to foster more supportive and accepting attitudes and improved pastoral care to reduce the impact of the unwanted consequences on students' long term level of wellbeing (Galbraith, Brown, \& Clifton, 2014). Support and early intervention will also facilitate improved academic outcomes (Storrie, Ahern, \& Tuckett, 2010).

To increase awareness of the impact of mental health problems on student educational outcomes research was conducted at two Australian universities during mental health week in October 2013. Emails were sent to all students and staff 
inviting them to participate in the research: (a) staff were asked to complete the "Attitude towards mental illness survey" (Health \& Social Care Information Centre, 2011); and (b) students who self-identified as having a mental health problem were asked to report their stigma experiences using the Stigma Scale developed by King et al. (2007). Promoting these surveys during mental health week aimed to increase awareness of mental health problems within the university sector and the impact that stigma and discrimination can have on a person's recovery process. Positive staff attitudes and support can facilitate this process as well as promoting students' help seeking behaviours in a supportive environment.

\section{$\underline{\text { METHOD }}$}

Ethics approval to conduct the study was obtained from the two universities' Human Research Ethics Committees. Approval to conduct the research was also obtained from University Management.

\section{Staff survey}

Permission to use the "Attitude towards mental illness survey" with staff was obtained in 2012 by the principal researcher from the National Health Service Health and Social Care Information Centre in the United Kingdom. A telephone survey format has been used annually to collect data in the United Kingdom since 2007 with an average of 1700 participants per annum (King et al., 2007). An online format was used in this current research. Although the validity and reliability are not reported, the Attitude towards mental illness survey has been used in the United Kingdom every year since 1994 (King et al., 2007). The survey has been reviewed by experts annually (King et al., 2007), which reflects a high level of content validity. The survey was comprised of 20 questions and took approximately 10 minutes to complete. There were four categories within the survey: (a) fear and exclusion of 
people with mental illness (b) understanding and tolerance of mental illness (c) integrating people with mental illness into the community $(d)$ causes of mental illness. Each category included a number of statements and respondents were asked to rate their level of agreement or disagreement with each of the statements, with $(1)=$ strongly agree to $(5)=$ strongly disagree. Additional questions covered topics such as descriptions of people with mental illness, relationships with people with mental illness, personal experience of mental illness, and perceptions of mental health-related stigma and discrimination. Participants were informed that completion of the survey was deemed as providing informed consent to participate and to have the findings published. A detailed information sheet was provided as the first page of the survey.

\section{Student survey}

The Stigma Scale developed by King et al. (2007) used qualitative data obtained from mental health service users to develop the 28 item self-report scale (King et al., 2007). Originally, the scale had a high level of internal consistency (Cronbach's alpha was 0.87) (King et al., 2007). In the current study, the internal consistency was 0.70 which still reflects an acceptable level of internal consistency (George \& Mallery, 2003).

This survey is in the public domain and students who self-identified as having a mental health problem were invited to participate in the research. The survey had a three factor structure: 1) discrimination, 2) disclosure and 3) potential positive aspects of mental illness. The questionnaire took 10 minutes to complete and was scored on a five point rating scale, with (1) =strongly agree and (5) = strongly disagree. While the researchers were confident students would not experience 
distress by completing the survey, safeguards were designed to address the possibility that some may. Contact details of the principal researcher were provided if students wanted to make contact: a) prior to starting the survey or b) regarding their experiences of completing the survey. In the event that completing the survey triggered a response to previous negative experiences, students were able to contact the principal researcher and to obtain professional support from counselling services at each university. Information on how to seek help at the university and the general community for the mental health problems they were experiencing was also provided at the beginning and end of the survey to encourage students to seek professional help.

\section{Data Storage}

Data for both studies were collected using a secure Survey Monkey website which was password protected and only accessed by two members of the research team. When the survey closed, data were transferred to the researchers' password protected computers at the university.

\section{Data Analysis}

Data collected for both surveys were analysed using the Statistical Package for Social Sciences, Version 22.0 (SPSS for Windows, SPSS Inc., Chicago, IL, USA)("Statistical Package for Social Sciences," 2013). Descriptive statistics and chi square were used to determine relationships between students with mental health problems and their experiences of discrimination and stigma. Descriptive statistics were used to identify staff attitudes towards mental illness.

\section{RESULTS}

\section{$\underline{\text { Staff }- \text { Attitudes Towards Mental Illness Survey }}$}


Staff response $=270$ with $25 \%(n=67)$ male, $67 \%(n=180)$ female and $8 \%(n=23)$ identifying as other; $51 \%(n=138)$ were academic staff and $49 \%(n=132)$ professional staff and $58 \%(n=156)$ had been working at the university for 5 years. In line with the 2011 Survey Report from the National Health Service in the United Kingdom, the 23 attitude statements were grouped into four categories for analysis purposes.

\section{$\underline{\text { 1. Fear and Exclusion of People with Mental Illness }}$}

Very positive responses towards people with mental illness were recorded for all questions within this category. Staff responses ranged from 93\% $(n=251)$ agreeing that 'people with mental illness should not be excluded from taking public office' to $86 \%(n=232)$ disagreeing that 'locating mental health facilities in a residential area downgrades the neighbourhood'. Staff responses indicated less fear of people with mental illness with $95 \%(n=256)$ agreeable to living next door to someone with a mental illness and this was reflected in $96 \%(n=259)$ disagreeing that 'signs of mental disturbance require hospitalisation'.

\section{Understanding and Tolerance of Mental IIIness}

In this category, staff responses showed 90\% $(n=243)$ agreement that 'we have a responsibility to provide the best possible care for people with a mental illness' and $90 \%(n=243)$ acknowledged that 'anyone can develop a mental illness'. University rules of conduct promote tolerance, equity and social justice which increases staff awareness of diversity and discrimination and reflects the $92 \%(n=248)$ agreed response to the question 'we need to adopt a far more tolerant attitude toward people with mental illness in our society'.

\section{Integrating People with Mental IIIness into the Community}

In this category, the percentage of staff who agreed with integrating people with mental illness into the community varied across questions. The opinions ranged 
from $42 \%(n=113)$ who agreed that 'mental hospitals were an outdated means of treating mental illness', to $89 \%(n=240)$ agreeing that 'people with mental problems should have the same rights to a job as anyone else'. However only $50 \%(n=135)$ agreed there 'should be less emphasis placed on protecting the public from people with mental illnesses', and only $50 \%(n=135)$ agreed 'most women who were once patients in a mental hospital could be trusted as babysitters'.

\section{Causes of Mental IIIness}

In the fourth category, $96 \%(n=259)$ disagreed that 'lack of self-discipline and will power were the main causes of mental illness' and 96\% $(n=259)$ disagreed that 'there was something about people with mental illness that makes them easy to identify from normal people'. The respondents were then asked to what extent they agreed or disagreed that each of the following was a type of mental illness:

schizophrenia; depression; stress; grief; bipolar disorder (manic depression); drug addiction. The highest response was $78 \%(n=210)$ to depression as the most descriptive of a person with mental illness and possibly reflects the impact that public education campaigns such as 'Beyond Blue' ${ }^{30}$ have played in explaining depression as a mental illness in Australia. Only $24 \%(n=65)$ of respondents attributed violence to people who had a mental illness. Seventy two percent $(n=194)$ agreed that 'people with a mental illness were responsible for their actions and inferred that mental illness does not preclude taking personal responsibility. See Figure 1 for more information on responses to the types of mental illness.

\section{Insert Figure 1 here}

The questions about relationships with people with mental illness identified that staff were more likely to be involved with someone who had a mental illness and more likely in the future to be associated with someone with a mental illness. In response 
to the question "who is the person closest to you who has or has had some kind of mental illness", the staff responses indicated an increased contact and association with someone with a mental illness including themselves. Staff recognition of family members, friends and work colleagues with mental health problems possibly highlights the success of media campaigns to disclose and seek help for mental health problems to decrease the stigma associated with mental illness. Figure 2 provides the breakdown of staff response to knowing someone with a mental illness. Insert Figure 2 here

Finally, staff indicated that talking to friends and family about their level of mental health remained difficult, with $54 \%(n=146)$ responding they would feel uncomfortable discussing mental health problems with family and friends. Eighty nine percent $(n=240)$ reported that they did not feel comfortable discussing issues related to their mental health with their employer. Their response to perceived changes in mental health related stigma and discrimination over the past year revealed that $50 \%(n=135)$ of staff saw no change.

\section{Student stigma survey results}

A total of 201 students completed the online survey: $78 \%(n=157)$ were female, $22 \%$ $(n=44)$ males; $88 \%(n=177)$ were undergraduate students and $12 \%(n=24)$ were completing master and/or doctoral degrees. Ninety five percent of participants were Australian students $(n=191)$ and five percent $(n=10)$ were international students. Participant ages ranged from 17 to $51+$ years with mean age of 28 years. In reporting the results for the stigma scale and its subscales, the higher the mean the more agreement there is with the statement in that category. Results are provided in Table one. 
Insert Table 1 here

Not informing employers that they had a mental health problem was the most frequently reported finding with more than three quarters $76 \%(n=153)$ of students not admitting they have had a problem when applying for a job. Furthermore, $84 \%$ $(\mathrm{n}=169)$ of participants agreed that having had a mental health problem made them a more understanding person. There were no significant differences between undergraduate and postgraduate students for any category, but more than $69 \%$ $(n=137)$ of Australian students agreed they "felt alone because of their mental health problems" whilst only $30 \%(n=60)$ of international students acknowledged this experience.

Discrimination was experienced across all student age groups, but mainly in the older age group. Since the $\mathrm{P}$ value is less than 0.05 , older students experienced significantly greater discrimination in response to the following questions: "I have been discriminated against in education because of my mental health problems" $\mathrm{X}^{2}$ (df, 28, n 201)=46.967, p=0.014; "Sometimes I feel that I am being talked down to because of my mental health problems" $X^{2}(d f, 28, n, 201)=44.032, p=0.027$; "I have been discriminated by employers because of my mental health problems" $X^{2}$ (df, $28, n$ $200)=55.376, p=.002$. Since the $P$ value is less than 0.01 , a significant positive relationship existed between stigma and discrimination $(r=0.866, n 201, p=0.00)$ from one side and disclosure and stigma from other side $(r=0.323, n$ 201, $p=0.00)$. Students who responded that they had experienced discrimination because of their problems also experienced stigma associated with fear of disclosure of these problems. The participants perceived limited positive outcomes from their mental health problems with no significant association between stigma and positive 
aspects of mental illness. A significant negative correlation was also found between discrimination and positive aspects of mental illness ( $r=-0.193, n 201, p=0.006)$.

\section{DISCUSSION}

A theme highlighted in the findings of both surveys was the 'silence' associated with mental health problems and it permeated the university environment in many ways. 'Silence' was identified through the low participation rates by staff and students to research extensively promoted at the two universities. Based on the Australian National survey of mental health and wellbeing data (2007), it was estimated that up to $20 \%$ of the university population would have experienced a mental illness in the last 12 months but due to the low response rates obtained, the extent of the experiences could not be accurately explored (Australian Bureau of Statistics, 2009). The low response rates are recognised as limitations of the research.

While there has been an increase in the awareness of mental health problems in university student populations over the last few years (Hunt \& Eisenberg, 2010; Khawaja \& Dempsey, 2007; Leahy et al., 2010; Stallman, 2010; Wynaden et al., 2013), the findings identified a new dimension of 'silence' surrounding mental health problems in university staff and the resulting impact on staff and university productivity requires further investigation. As mental illnesses are the leading cause of disability burden in Australia and account for an estimated $24 \%$ of the total years of lost employment due to disability, an increased awareness of the social and economic impact of mental health problems on university staff is strategically important (Begg et al., 2007).

The majority of staff and students who did respond to the surveys stated they would not inform their employer of their problem creating another dimension to the 'silence,' non-disclosure. Researchers in a New Zealand study also reported that $57 \%$ of 
participants had concealed or hidden their mental health problems from others (Thornicroft, Wyllie, Thornicroft, \& Mehta, 2014). Students in this current study showed a positive correlation between stigma, discrimination and disclosure and this was similar to other international research (Eisenberg, Downs, Golberstein, \& Zivin, 2009). The failure of students to disclose mental health problems to employers for fear of being discriminated against is also transferable to the university. The fear of being discriminated against creates a reluctance to disclose and as a result, affected students experience isolation, loneliness and struggle as they try to meet their study requirements. This leads many students to withdraw prior to completing their educational program (Wynaden et al., 2013). International students may also be reluctant to disclose mental health problems as they may fear that their student visa and course enrolment may be cancelled.

Academic staff are routinely provided with information about how to access counselling services and disability support services (Storrie et al., 2010), and all students have the opportunity to receive information about general and mental health services available on campus. While effective support is fundamental to mental health recovery, other researchers have found that universities struggle to cope successfully with the increased severity and numbers of students requiring mental health support (Cook, 2007; Khawaja \& Dempsey, 2007; Mowbray et al., 2006; Stallman, 2010).

When non-professional support is provided, it is a 'silent' contribution from academic or professional staff. This type of support is usually unacknowledged and untracked and staff willingness to engage and provide pastoral care to students is balanced against their own mental health needs, their competing workload and an increasingly 
challenging and complex work environment (Galbraith et al., 2014; McAllister et al., 2014).

Many of the staff who answered the survey had previous exposure to people with a mental illness and their high levels of tolerance and understanding could be attributed to these experiences. These staff may be knowledgeable but often lacked formal support, supervision within the university environment and so their ability to bring about change is silenced.

There is a move to increase the mental health literacy of academic and professional staff through educational programs such as Mental Health First Aid (Jorm et al., 1997). Mental health literacy includes the ability to recognise specific disorders, knowledge of causes and risk factors, of self- treatments, and of professional help available and attitudes that promote recognition and appropriate help-seeking (Jorm et al., 1997). Research on the use of Mental Health First Aid with teachers at seven high schools in South Australia reported positive changes in attitudes to people with mental health problems and an increased awareness and knowledge of help seeking behaviours in students (Jorm, Kitchener, Sawyer, Scales, \& Cvetkovski, 2010). However, results from a systematic review in 2011 of mental illness-related beliefs and attitudes in the general population found that increasing public understanding of the causes of mental illness does not result in improved social acceptance of persons with mental health problems (Schomerus et al., 2012). Some researchers argue that such campaigns may support medicalised agendas and take over from the voices of those who have experienced stigma (Yap, Reavley, Mackinnon, \& Jorm, 2013). Other aspects of community support need to be promoted and incorporated into university strategic initiatives particularly those that promote that 
mental health recovery is possible and the problem can be overcome. While mental health literacy is now being actively promoted throughout the tertiary settings in Australia, stigma and discrimination persist and the current resources do not appear to change the level of stigma attached to mental health problems, increased help seeking, nor does it mean people have understood what constitutes a mental health problem (Arria et al., 2011; Bell et al., 2010). Furthermore, international research suggests that the general public maintains a low level of mental health literacy and stigma and discrimination continue to affect people who have mental health problems and this in turn reduces their help seeking behaviour, perpetuating their problems (Corrigan \& Rao, 2012; Evans-Lacko, Brohan, Mojtabai, \& Thornicroft, 2012 ; Munizza et al., 2013). A review of the effectiveness of anti-stigma mass media campaigns showed prejudice towards people with mental health problems decreased, but there was limited evidence to show a change in discrimination (Clement et al., 2013 ). There is also evidence that stigmatising attitudes can impact on young people's initiative to provide mental health support to their peers experiencing mental health problems (Yap \& Jorm, 2011). Furthermore, health professionals were found to maintain a level of discrimination against people who presented with mental health problems (Reavley, Mackinnon, Morgan, \& Jorm, 2013) which further decreased this groups' help seeking behaviours (Shrivastava, Bureau, Rewari, \& Johnston, 2013). A recent review of public attitudes in the United Kingdom showed that despite improvements in mental health literacy, negative public attitudes and desire for social distance from people with mental problems have remained stable over time (Evans-Lacko, Henderson, \& Thornicroft, 2013). 
The avoidance of help-seeking of staff and students experiencing mental health problems is of strategic importance to universities as social inclusion is central to mental health recovery and a person's ability to complete their education program or work commitments. Research has shown that close interactions with someone who has a mental illness, empathy (Rusch et al., 2014) and increased social activism to promote the importance of mental health and wellbeing are also effective ways of decreasing stigma (Corrigan, Morris, Michaels, Rafacz, \& Rüsch, 2012). Specifically, the use of people with a lived experience of mental health problems was found to increase empowerment and reduce stigma for those currently facing difficulties (Segal, Silverman, \& Temkin, 2010). For example, inviting the input of mental health service users who have successfully completed tertiary studies in education and training with staff and students could be another option to change attitudes, in addition to offering Mental Health First Aid (Repper \& Perkins, 2003). This approach has been trialled with nursing students with success in Australia and internationally (Blackhall, Schafer, Kent, \& Nightingale, 2012; Byrne, Happell, Welch, \& Moxham, 2013; Gutmana, Kraiema, Cridena, \& Yalon-Chamovitz, 2012 ), and demonstrated that mental health service users reduced the level of stigma through their educational and training programs and were a source of support for both students and staff experiencing mental health problems (Ochocka, Nelson, Janzen, \& Trainor, 2006; Segal et al., 2010).

Mental health week and World Mental Health Day are also opportunities for universities to focus on identifying and recruiting champions within the university to talk about their experiences and recovery strategies. Innovative ways to increase help seeking, privacy and timely access for students with mental health problems and provision of realistic support for staff are also urgent priorities (Leahy et al., 
2010). Most universities now have a large multicultural student base and all interventions need to be tailored to the diversity of the university population. Specific mental health issues for Indigenous, gay, lesbian, bisexual, transgender and intersex (GLBTI) and CALD students, particularly those from a refugee background that have experienced trauma in their resettlement need culturally appropriate responses (Eley et al., 2007; Hannah, 1999). Embedding recovery orientated mental health information in first year units across disciplines could be a significant step towards social inclusion and advocacy for people experiencing mental health problems (Salzer, 2012). Reducing the stigma and discrimination attached to mental illness can also be achieved through the evolving language used to describe the experiences that people have. Increasingly, the term mental health challenge is being used as an alternative to problem, illness and disorder. The term is viewed as consistent with mental health recovery and a strengths based term that recognises the challenge faced by the individual can be overcome and the person can achieve their goals and live productively within the community (Australian Health Ministers Advisory Council, 2013).

To build university environments that foster mental wellbeing, orientation week could include a variety of programs including mental health literacy, access to mental health service users through support programs, orientation to online helping resources such as self-help, online mentors, FAQs and online counselling for students. Staff support and opportunities to learn how to offer reassurance, emotional strength, and acceptance to students with mental health problems could be part of orientation to all new staff and available through the counselling services 
on a regular basis for current staff (Substance Abuse and Mental Health Services Administration, 2006).

Developing a safe and secure web based help line with online messaging links with a health service provider would offer a confidential avenue for students who are reluctant to access on campus health services for their mental health problems and has proved useful in several other studies concerning health information access (Alishahi-Tabriz, Sohrabi, Kiapour, \& Faramarzi, 2013; Lau et al., 2013). In other countries, web-based education has been found to be effective in enhancing selfawareness and reducing mental illness stigma among university students (Finkelstein, Lapshin, \& Wasserman, 2007; Kim et al., 2011). Similarly, in Australia, Web-2 systems have also been recognised as important collaborative and interactive data bases for mental health education and information (Bastida, McGrath, \& Maude, 2010).

\section{CONCLUSION}

Universities are increasingly diverse environments with opportunities to enhance knowledge development and cultural enrichment. However, for this to occur and for individuals to reach their learning potential, health and wellbeing must be enabled. Health is much more than the absence of disease, and includes mental health. This paper highlights the ongoing barriers to health including hidden and overt sources of stigma. Overcoming these social problems requires multi-pronged proactive measures, including mental health literacy and empathy programs, expansion of health and pastoral service provision, and the engendering of a culture that appreciates difference. 


\section{$\underline{\text { REFERENCES }}$}

Ahern, N. (2009). Risky behavior of adolescent college students. Journal of Psychosocial Nursing and Mental Health Services, 47(4), 21-25. DOI: http://dx.doi.org/10.3928/02793695-20090401-02

Alishahi-Tabriz, A., Sohrabi, M. R., Kiapour, N., \& Faramarzi, N. (2013). Addressing the changing sources of health information in iran. International Journal Preventive Medicine, 4(1), 33-41.

Arria, A. M., Winick, E. R., Garnier-Dykstra, L. M., Vincent, K. B., Caldeira, K. M., Wilcox, H. C., \& O'Grady, K. E. (2011). Help seeking and mental health service utilization among college students with a history of suicide ideation. Psychiatric Services, 62(12), 1510-1513. DOI: http://dx.doi.org/10.1176/appi.ps.005562010

Australian Bureau of Statistics. (2009). National Survey of mental health and wellbeing: Summary of Results 2007. (catalogue number 4327.0). Canberra: Australian Bureau of Statistics

Australian Health Ministers. (2007). What is mental illness?. In National Mental Health Strategy (Ed.). Canberra: Department of Health and Ageing Commonweatlh of Australia.

Australian Health Ministers Advisory Council. (2013). A national framework for recovery orientated mental health services: Policy and theory. in: Department of Health, Ageing CoA (Eds.) Department of Health and Ageing, Commonwealth of Australia, Canberra.

Bayram, N., \& Bilgel, N. (2008). The prevalence and socioeconomic correlations of depression, anxiety and stress among a group of university students. Social Psychiatry and Psychiatric Epideminology, 43(8), 667-672. DOI: http://dx.doi.org/10.1007/s00127-008-0345-x

Begg, S., Vos, T., Barker, B., Stevenson, C., L., S., \& Lopez, A. (2007). The burden of disease and injury in Australia 2003. (cat. no. PHE 82). Canberra: Australian Institute of Health and Welfare.

Bell, J. S., Aaltonen, S. E., Airaksinen, M. S., Volmer, D., Gharat, M. S., Muceniece, R., ... Chen, T. F. (2010). Determinants of mental health stigma among pharmacy students in Australia, Belgium, Estonia, Finland, India and Latvia. International Journal of Social Psychiatry. 56(1), 3-14DOI:

http://dx.doi.org/10.1177/0020764008097621 
Blackhall, A., Schafer, T., Kent, L., \& Nightingale, M. (2012). Service user involvement in nursing students' training. Mental Health Practice, 16(1), 2326. DOI: http://dx.doi.org/10.7748/mhp2012.09.16.1.23.c9280

Burris, J., Brechting, E., Salsman, J. \& Carlson, C. (2009). Factors associated with the psychological wellbeing and distress of university students, Journal of American College Health 57(5), 536-544. DOI: http://dx.doi.org/10.3200/JACH.57.5.536-544

Byrne, L., Happell, B., Welch, T., \& Moxham, L. J. (2013). 'Things you can't learn from books': Teaching recovery from a lived experience perspective. International Journal of Mental Health Nursing, 22(3), 195-204. DOI: http://dx.doi.org/10.1111/j.1447-0349.2012.00875.x

Clement, S., Lassman, F., Barley, E., Evans-Lacko, S., Williams, P., Yamaguchi, S., \& Thornicroft, G. (2013 ). Mass media interventions for reducing mental health-related stigma. Cochrane Database of Systematic Reviews, 23. CD009453. http://dx.doi.org/10.1002/14651858.CD009453.pub2

Cook, L. J. (2007). Striving to help college students with mental health issues. Journal of Psychosocial Nursing and Mental Health Services , 45(4), 40-44.

Corrigan, P., Morris, S., Michaels, M., Rafacz, D., \& Rüsch, N. (2012). Challenging the Public Stigma of Mental Illness: A Meta-Analysis of Outcome Studies. Psychiatric Services, 63, 963-973. . DOI: http://dx.doi.org/10.1192/apt.bp.106.002857

Corrigan, P. W., \& Rao, D. ( 2012). On the self-stigma of mental illness: stages, disclosure, and strategies for change. Canadian Journal of Psychiatry, 57(8), 464-469

Eisenberg, D., Downs, M. F., Golberstein, E., \& Zivin, K. (2009). Stigma and help seeking for mental health among college students. Medical Care Research and Review, 66(5), 522-541DOI: http://dx.doi.org/10.1177/1077558709335173.

Eley, D., Young, L., Hunter, K., Baker, P., Hunter, E., \& Hannah, D. ( 2007 ). Perceptions of mental health service delivery among staff and Indigenous consumers: it's still about communication. Australasian Psychiatry, 15(2), 130 134DOI: http://dx.doi.org/10.1080/10398560601121017.

Evans-Lacko, S., Brohan, E., Mojtabai, R., \& Thornicroft, G. (2012 ). Association between public views of mental illness and self-stigma among individuals with mental illness in 14 European countries. Psychological Medicine, 42(8), 17411752DOI: http://dx.doi.org/10.1017/S0033291711002558.

Evans-Lacko, S., Henderson, C., \& Thornicroft, G. (2013). Public knowledge, attitudes and behaviour regarding people with mental illness in England 2009- 
2012. The British Journal of Psychiatry, 202(s55), s51-s57. DOI: http://dx.doi.org/10.1192/bjp.bp.112.112979

Field, T., Diego, M., Pelaez, M., Deeds, O. \& Delgado, J. (2008). Breakup distress in university students. Adolescence, 44(176), 705-727.

Galbraith, N. D., Brown, K. E., \& Clifton, E. (2014). A Survey of Student Nurses' Attitudes Toward Help Seeking for Stress. Nursing Forum. DOI: http://dx.doi.org/10.1111/nuf.12066

George D, \& Mallery, P. (2003).SPSS for Windows step by step: A simple guide and reference. 11.0 update Vol. 4th ed. Boston: Allyn \& Bacon.

Gutmana, C., Kraiema, Y., Cridena, W., \& Yalon-Chamovitz, S. (2012 ). Deconstructing Hierarchies: A Pedagogical Model with Service User CoTeachers. Social Work Education: The International Journal 31,( 2), 202-214 DOI: http://dx.doi.org/10.1080/02615479.2012.644963

Hannah, J. (1999). Refugee Students At College And University: Improving Access And Support. International Review of Education, 45(2), 153-166. DOI: http://dx.doi.org/10.1023/A:1003640924265

Health \& Social Care Information Centre. (2011). Attitudes to mental illness (pp. 31). England: NHS Information Centre.

Henderson, C., Evans-Lacko, S., \& Thornicroft, G. (2013). Mental illness stigma, help seeking, and public health programs. American Journal of Public Health, 103(5), 777-780. DOI: http://dx.doi.org/10.2105/AJPH.2012.301056

Hunt, J., \& Eisenberg, D. (2010). Mental health problems and help-seeking behaviour among college students. Journal of Adolescent Health, 46, 3-10. 10DOI: http://dx.doi.org/10.1016/j.jadohealth.2009.08.008

Jorm, A. F., Kitchener, B. A., Sawyer, M. G., Scales, H., \& Cvetkovski, S. (2010). Mental health first aid training for high school teachers: a cluster randomized trial. BMC Psychiatry, 10, 51. DOI: http://dx.doi.org/10.1186/1471-244x-10-51

Jorm, A. F., Korten, A. E., Jacomb, P. A., Christensen, H., Rodgers, B., \& P., P. (1997). "Mental health literacy": a survey of the public's ability to recognise mental disorders and their beliefs about the effectiveness of treatment. The Medical Journal of Australia, 166, 182-186. DOI: http://dx.doi.org/10.1192/bjp.177.5.396

Khawaja, N. G., \& Dempsey, J. (2007). Psychological distress in international university students: An Australian study. Australian Journal of Guidance and Counselling, 17(1), 13-27. DOI: http://dx.doi.org/10.1375/ajgc.17.1.13 
Kim, E., Coumar, A., Lober, W., \& Kim, Y. (2011). Addressing mental health epidemic among university students via web-based, self-screening, and referral system: A preliminary study. IEEE Transactions on Information Technology in Biomedicine 15(2), 301-307. DOI: http://dx.doi.org/10.1109/TITB.2011.2107561

King, M., Dinos, S., Shaw, J., Watson, R., Stevens, S., Passetti, F., ... Serfaty, M. (2007). The stigma scale: Development of a standardised measurement of the stigma of mental illness. British Journal of Psychiatry, 190, 248-254. DOI: http://dx.doi.org/10.1192/bjp.bp.106.024638

Lau, A. Y., Proudfoot, J., Andrews, A., Liaw, S. T., Crimmins, J., Arguel, A., \& Coiera, E. (2013). Which bundles of features in a Web-based personally controlled health management system are associated with consumer helpseeking behaviors for physical and emotional well-being? Journal of Medical Internet Research, 15(5), e79DOI: http://dx.doi.org/10.2196/jmir.2414

Leahy, C., Peterson, R., Wilson, I., Newby, J., Tonkin, A., \& Turnbull, D. (2010). Distress levels and self-reported treatment rates for medicine, law, psychology and mechanical engineering tertiary students: Cross sectional study. Australian and New Zealand Journal of Psychiatry, 44(7), 608-615. Dol: http://dx.doi.org/10.3109/00048671003649052

McAllister, M., Wynaden, D., Walters, V., Flynn, T., Duggan, R., Byrne, L., \& Happell, B. (2014). An exploration of the experiences of university staff in working with students who are managing a mental health problem. Final Report. Noosa: CQUniversity Australia.

Michaels, P., López, M., Rüsch, N., \& Corrigan, P. (2012). Constructs and concepts comprising the stigma of mental illness. Psychology, Society and Education, 4(2), 183-194.

Mori, S. (2000). Addressing the mental health concerns of international students. Journal of Counselling Development, 78(2), 137-144. DOI: http://dx.doi.org/10.1002/j.1556-6676.2000.tb02571.x

Mowbray, C. T., Megivern, D., Mandiberg, J. M., Strauss, S., Stein, C. H., Collins, K., ... Lett, R. (2006). Campus mental health services: recommendations for change. The American Journal of Orthopsychiatry, 76(2), 226-237. DOI: http://dx.doi.org/10.1037/0002-9432.76.2.226

Munizza, C., Argentero, P., Coppo, A., Tibaldi, G., Di Giannantonio, M., Picci, R. L., \& Rucci, P. (2013). Public beliefs and attitudes towards depression in Italy: a national survey. PLoS One, 8(5), e63806. DOI: http://dx.doi.org/10.1371/journal.pone.0063806 
Ochocka, J., Nelson, G., Janzen, R., \& Trainor, J. (2006). A longitudinal study of mental health consumer/survivor initiatives: Part 3- a qualitative study of impacts of participation on new members. Journal of Community Psychology, 34(3), 273-283. DOI: http://dx.doi.org/10.1002/jcop.20099

Raunic, A., \& Xenos, S. (2008). University counselling service utilisation by local and international students and user characteristics: A review. International Journal for the Advancement of Counselling, 30(4), 262-267. DOI:

http://dx.doi.org/10.1007/s10447-008-9062-0

Reavley, N. J., Mackinnon, A. J., Morgan, A. J., \& Jorm, A. F. (2013). Stigmatising attitudes towards people with mental disorders: A comparison of Australian health professionals with the general community. The Australian and New Zealand Journal of Psychiatry. 48(5): 433-441. DOI: http://dx.doi.org/10.1177/0004867413500351

Repper, J., \& Perkins, R. (2003). Social inclusion and recovery: A model for mental health practice Edinburgh: Bailliere Tindall.

Rusch, N., Muller, M., Lay, B., Corrigan, P., Zahn, R., Schonenberger, T., ... Rossler, W. (2014). Emotional reactions to involuntary psychiatric hospitalization and stigma-related stress among people with mental illness. European Archives of Psychiatry and Clinical Neuroscience, 264, 35-43. DOI: http://dx.doi.org/10.1007/s00406-013-0412-5

Salzer, M. S. (2012). A comparative study of campus experiences of college students with mental illnesses versus a general college sample. Journal of the American College of Health, 60(1), 1-7. DOI: http://dx.doi.org/10.1080/07448481.2011.552537

Schomerus, G., Schwahn, C., Holzinger, A., Corrigan, P. W., Grabe, H. J., Carta, M. G., \& Angermeyer, M. C. (2012). Evolution of public attitudes about mental illness: a systematic review and meta-analysis. Acta Psychiatrica Scandinavica, 125(6), 440-452DOI: http://dx.doi.org/10.1111/j.16000447.2012.01826.x

Shrivastava, A., Bureau, Y., Rewari, N., \& Johnston, M. (2013). Clinical risk of stigma and discrimination of mental illnesses: Need for objective assessment and quantification. Indian Journal of Psychiatry, 55(2), 178-182. DOI: http://dx.doi.org/10.4103/0019-5545.111459

Stallman, H. M. (2008). Prevalence of psychological distress in university students Implications for service delivery. Australian Family Physician, 37(8), 673-677.

Stallman, H. M. (2010). Psychological distress in university students: A comparison with general population data. Australian Psychologist, 45(4), 249-257. 257DOI: http://dx.doi.org/10.1080/00050067.2010.482109 
Stallman, H. M., \& Shochet, L. (2009). Prevalence of mental health problems in Australian university health services. Australian Psychologist, 44(2), 122 127. DOI: http://dx.doi.org/10.1080/00050060902733727

Statistical Package for Social Sciences [computer program] (Version Version 22.0). (2013). Chicago;IL, USA: SPSS Inc.

Storrie, K., Ahern, K., \& Tuckett, A. (2010). A systematic review: Students with mental health problems--a growing problem. International Journal of Nursing Practice, 16(1), 1-6. 6DOI: http://dx.doi.org/10.1111/j.1440-172X.2009.01813.x

Substance Abuse and Mental Health Services Administration. (2006). Developing a Stigma Reduction Initiative. SAMHSA Pub No. SMA-4176. In: Center for Mental Health Services. Rockville, MD: U.S. Department of Health and Human Services.

Thornicroft, C., Wyllie, A., Thornicroft, G., \& Mehta, N. (2014). Impact of the "Like Minds, Like Mine" anti-stigma and discrimination campaign in New Zealand on anticipated and experienced discrimination. Australian and New Zealand Journal of Psychiatry, 48(4), 360-370. DOI: http://dx.doi.org/10.1177/0004867413512687

Wynaden, D., Chapman, R., Orb, A., McGowan, S., Yeak, S., \& Zeeman, Z. (2005). Factors that influence people from Asian communities access to and delivery of mental health care. International Journal of Mental Health Nursing, 14(2), 88-95. DOI: http://dx.doi.org/10.1111/j.1440-0979.2005.00364.x

Wynaden, D. G., Wichmann, H. M., \& Murray, S. (2013). A synopsis of the mental health concerns of university students: results of a text-based online survey from one Australian university. Higher Education Research and Development, 32(5), 1-15. DOI: http://dx.doi.org/10.1080/07294360.2013.777032.

Yap, M. B., \& Jorm, A. F. (2011). The influence of stigma on first aid actions taken by young people for mental health problems in a close friend or family member: Findings from an Australian national survey of youth Journal of Affective Disorders, 134(1-3), 473-477. DOI: http://dx.doi.org/10.1016/j.jad.2011.05.039

Yap, M. B. H., Reavley, N., Mackinnon, A. J., \& Jorm, A. F. (2013). Psychiatric labels and other influences on young people's stigmatizing attitudes: Findings from an Australian national survey. Journal of Affective Disorders, 148(2-3), 299309. DOI: http://dx.doi.org/10.1016/j.jad.2012.12.015

Yorgason, J., Linville, D.\& Zitzman, B. (2008). Mental health among college students: Do those who need services know about and use them. Journal of American College Health, 57(2), 173-182. DOI: http://dx.doi.org/10.3200/JACH.57.2.173-182 
Zartaloudi, A., \& Madianos, M. (2010). Stigma related to help-seeking from a mental health professional. Health Science Journal, 4(2), 77-83. 
Figure 1: Responses to identified types of mental illness

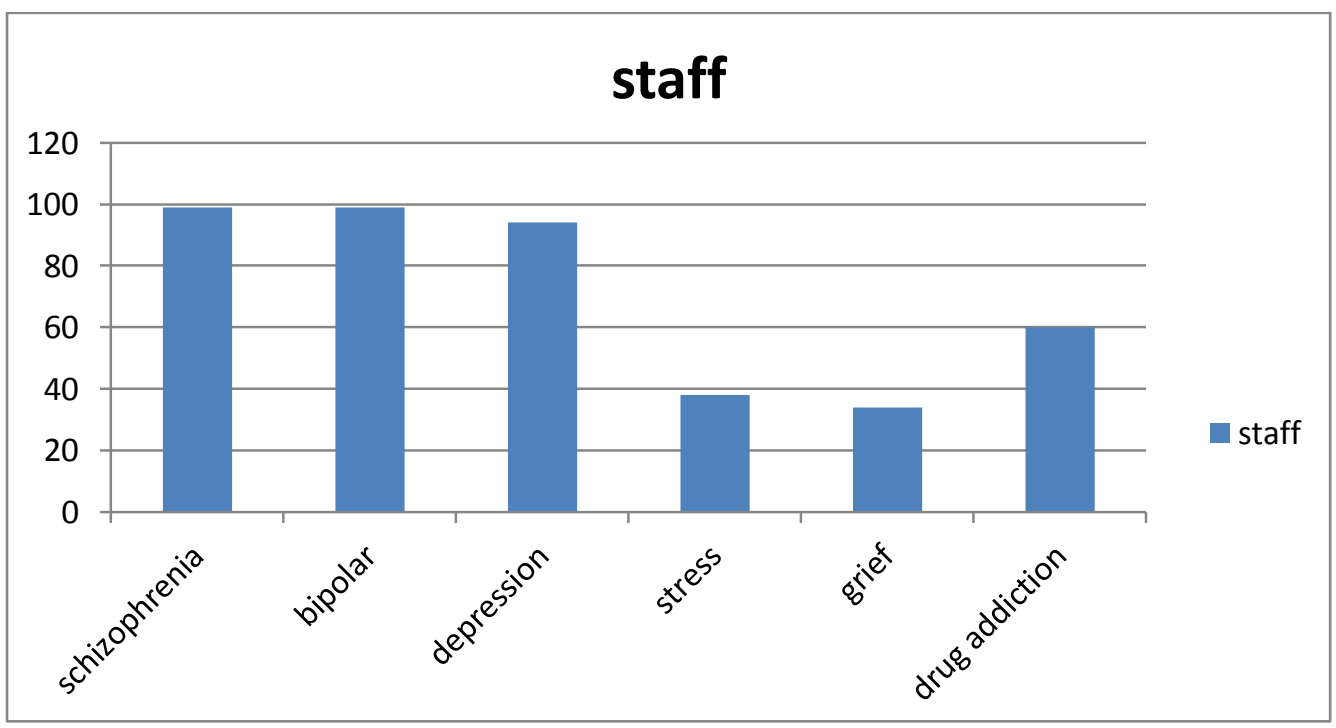


Figure 2: Percentage of staff responses to "Who is the person closest to you who has or has had some kind of mental illness"

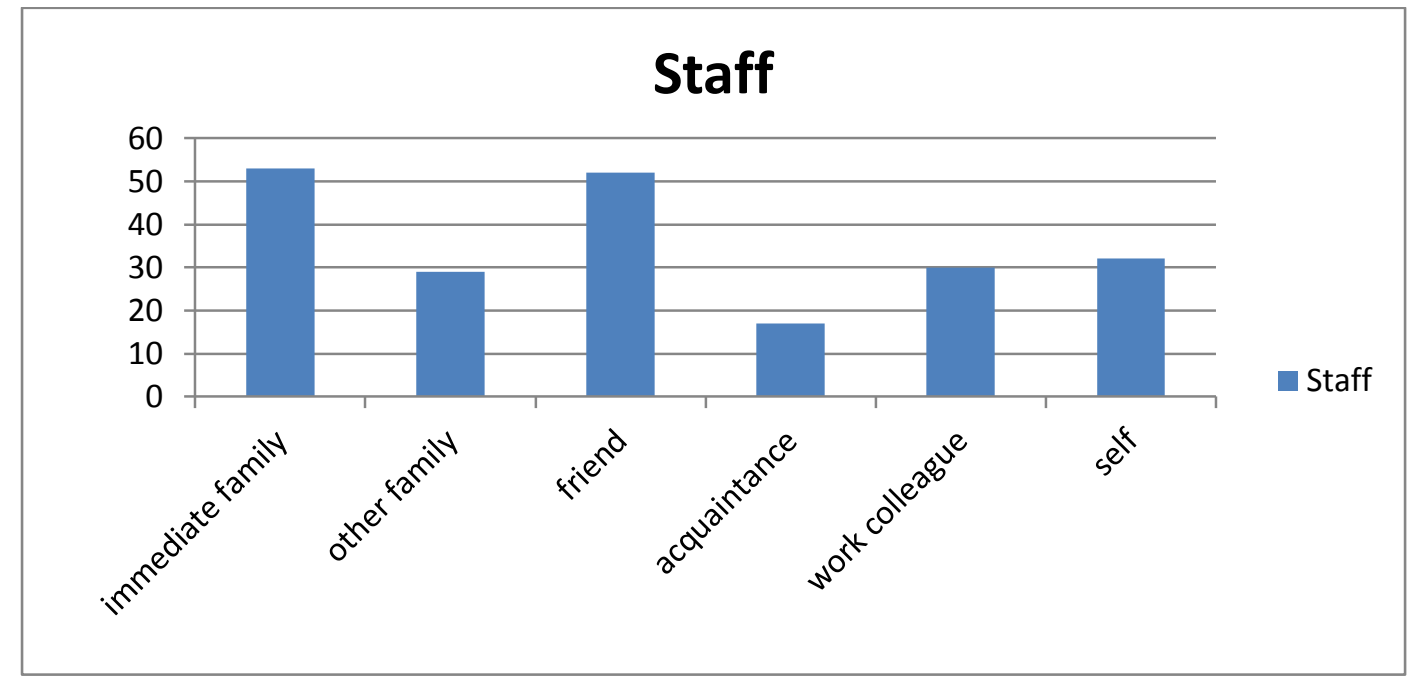


Table 1: Student responses including sub scale responses

\begin{tabular}{|l|c|c|c|}
\hline Sub scales & Items & Mean (SD) & Range \\
\hline Stigma scale & 28 & $2.87(.395)$ & $2.00-4.79$ \\
\hline Discrimination Sub scales & 13 & $3.17(.64)$ & $1.31-5.0$ \\
\hline Disclosure Sub scales & 10 & $2.82(.45)$ & $1.4-4.8$ \\
\hline Positive aspects Sub scales & 5 & $2.21(.62)$ & $1.0-4.2$ \\
\hline
\end{tabular}

